Religious Studies (2022) 58, 379-400 ㄷ The Author(s), 2021. Published by Cambridge University Press. This is an Open Access article, distributed under the terms of the Creative Commons Attribution licence (http://creativecommons.org/licenses/by/4.0/), which permits unrestricted re-use, distribution, and reproduction in any medium, provided the original work is properly cited. doi:10.1017/S0034412520000529

\title{
A new epistemological case for theism
}

\author{
CHRISTOPHE DE RAY (10) \\ Department of Philosophy, King's College London, Strand, London WC2R 2LS, UK \\ e-mail: christophe.de_ray@kcl.ac.uk
}

\begin{abstract}
Relying on inference to the best explanation (IBE) requires one to hold the intuition that the world is 'intelligible', that is, such that states of affairs at least generally have explanations for their obtaining. I argue that metaphysical naturalists are rationally required to withhold this intuition, unless they cease to be naturalists. This is because all plausible naturalistic aetiologies of the intuition entail that the intuition and the state of affairs which it represents are not causally connected in an epistemically appropriate way. Given that one ought to rely on IBE, naturalists are forced to pick the latter and change their world-view. Traditional theists, in contrast, do not face this predicament. This, I argue, is strong grounds for preferring traditional theism to naturalism.
\end{abstract}

\section{Introduction: epistemological arguments for theism}

Thus I see plainly that the certainty and truth of all knowledge depends uniquely on my awareness of the true God, to such an extent that I was incapable of perfect knowledge about anything else until I became aware of him. And now it is possible for me to achieve full and certain knowledge of countless matters ... (Descartes (1641), 49)

Descartes argued that one cannot have any knowledge of the external world unless one is a theist. This conclusion, when conjoined with the premise that we ought to think of ourselves as having such knowledge, yields the further conclusion that we ought to be theists.

Naturally, then, theistic philosophers inspired by Descartes have advanced what we may call 'epistemological arguments for theism'. The most famous of these is surely the one put forward by Alvin Plantinga (1993, 2011), who argued that the reliability of our cognitive faculties is to be expected given traditional theism, but not given metaphysical naturalism (understood as the 
view that there is no God, or anything like God). ${ }^{1}$ Robert Koons (2000), Tyler McNabb (2015), Jeffrey Koperski (2017), and others have produced similar arguments. Such arguments typically contend that reliance on some faculty or mode of inference is justified only if theism is true, or if those who rely on it are theists.

I will present and defend such an argument, and make the case that metaphysical naturalists cannot justifiably retain a philosophical intuition underpinning inference to the best explanation (IBE). Given that one ought to rely on IBE, it follows from this that one ought to cease to be a naturalist. Since traditional theists are not likewise compelled to withhold the intuition, this is strong reason to prefer traditional theism over naturalism.

While epistemological arguments for theism based on IBE already exist in the literature, my argument has some distinguishing features which, as I will argue, make it immune to some serious objections faced by its predecessors. In particular, I will motivate the claim that relying on IBE requires one to hold the intuition that the world is 'intelligible' in a sense to be explained shortly, and that there is no plausible naturalistic aetiology of this intuition on which there is an epistemically appropriate causal connection between our possession of the intuition on one hand, and the state of affairs that it represents on the other. This is importantly different from the more common claim that, given atheism or naturalism, we would not expect IBE to be reliable.

I begin by presenting my argument, before motivating and defending its premises. I then compare it to other arguments, in order to draw out its advantages.

\section{The argument}

My argument is as follows:

(1) There is no plausible naturalistic aetiology of the intelligibility intuition, such that we have the intuition because it is true.

(2) If (1) is correct, naturalists ought to withhold either the intelligibility intuition, or naturalism.

(3) One should not withhold the intelligibility intuition.

(4) Therefore, naturalists ought to withhold their belief in naturalism.

I will take 'naturalism' to refer to the metaphysical position to the effect that reality is exhausted by the natural order. ${ }^{2}$ The argument itself makes no mention of traditional theism, which I take to be the view that the natural order depends on God for its existence. ${ }^{3}$ However, and as I will argue, there is no available 'parallel' argument concluding with the need to withhold one's theistic beliefs. Thus, the soundness of my argument would constitute a strong consideration in favour of theism - especially if theism and naturalism are taken to be the only live options, as is common in contemporary philosophy of religion. 


\section{MOTIVATING (1)}

(1) There is no plausible naturalistic aetiology of the intelligibility intuition, such that we have the intuition because it is true.

I take the 'intelligibility intuition' to be a philosophical intuition to the effect that the world is 'intelligible', in a sense that will be clarified in this section. A naturalistic aetiology of the intelligibility intuition, then, is an account of the origins of this intuition that is consistent with naturalism, as I have defined it. Finally, the 'because' in this premise is to be taken in a causal sense, such that the truth of the intuition causes it to be the case that we have it.

\section{IBE and the intelligibility of the world}

Suppose you woke up one morning to find little dark pellets on the floor, and tiny bite marks on the cheese you'd left out last night. You realize that if there was a mouse in your house which lives in hiding during the day and comes out at night, this would explain these surprising states of affairs. In fact, it would best explain these states of affairs - as far as you can see, there isn't any other conceivable scenario given which they are equally well explained. You infer from this that there most likely is a mouse in your house.

In so doing, you will have drawn an inference to the best explanation (or if you prefer, an abductive inference). Peter Lipton's influential model of IBE offers a 'two-stage picture', whereby the 'generation of a short list of hypotheses' is followed by a 'selection from that list' (Lipton (2004), 151, emphases mine). When faced with some explanandum E, one first considers the different explanantia that could account for E, thereby producing a set of candidate theories. One then evaluates the candidates against each other, and identifies the 'best' of the lot, which is then inferred to be the true explanation of $\mathrm{E}$ (or, the likeliest of the lot).

IBE thus involves inferring that some candidate theory is true (or likely to be true) from the fact that it is the most explanatory - or as Lipton puts it, that it is the 'loveliest' (2004). To engage in IBE, then, is to treat explanatory loveliness as a guide to likeliness. Jaegwon Kim notes that 'to seek an explanation of something is to seek to understand it, to render it intelligible' (Kim (2010), 170). An explanation is 'lovely' to the extent that it would contribute to our understanding of the world if true, thereby rendering it 'intelligible' to us.

To treat explanatory loveliness as a guide to likeliness is surely to presuppose something about the overall character of the world - namely, that it is 'intelligible' in the sense that the theories which are true of it also happen to be lovely. There is, after all, no conceptual link between truth and explanatory loveliness. One can conceive of them coming apart. For example, I can imagine that nothing at all explains the appearance of pellets on the floor and strange marks on the cheese this morning. And I can imagine that the world contains many more such 
'brute' facts, lacking explanations as to their obtaining, let alone lovely ones. In this scenario, it would not be the case that the true theories also happen to be the loveliest ones (since the loveliest theories would ascribe explanations to many states of affairs which are in fact brute). Such a scenario would therefore be one in which inferring truth from explanatory loveliness is not a truth-conducive beliefforming method.

Thus, Lipton holds that relying on IBE requires one to believe that 'we live in the loveliest of all possible worlds' (Lipton (2004), 154). This is perhaps too strong. But relying on IBE does seem to require at the very least the belief that states of affairs at least generally have explanations for their obtaining - otherwise, why would one infer that a theory is true from the fact that its truth would explain some state of affairs? I will say that the world is intelligible if it is such that the states of affairs that obtain in it at least generally have explanations for their obtaining. ${ }^{4}$

To say that the world is 'intelligible' in this sense is to make a claim about the overall character of the world, not about our cognitive or epistemological limitations. Perhaps there are some facts, such as the non-existence of the A-series or the identity of the mind and the brain, that our finite minds can never truly grasp, in the sense of being able to understand how they can obtain. The world may still be intelligible in the sense at hand, even if some of its facts are intractably mysterious. ${ }^{5}$

\section{The intelligibility intuition}

Granted that we rely on IBE, and thus believe the world to be intelligible, how do we form this belief?

It may be thought that we believe it, simply because it aligns with what our best science says about the world. The picture that science paints of the world is one in which observable regularities are explained by more fundamental ones, and events are generally brought about by prior ones. The more science uncovers, the more intelligible the world appears. Perhaps, then, our belief in the intelligibility of the world is the result of an inference from the contents of the scientific world-view.

This account faces a serious difficulty - namely, that science itself is an abductive enterprise, not least because the objects of science are not typically directly observable. We can abductively infer the existence of macroscopic objects like mice, but we can also just see them. Since we cannot 'just see' electrons, black holes and the emergence of life on earth, theories about such entities will thus have to be abductively inferred from evidence that is itself directly observable. As a result, some have gone as far as to call abduction the 'inference that makes science' (McMullin, 1992). ${ }^{6}$

IBE is thus central to science, and most (if not all) scientific theories are formed through IBE. Now, we saw earlier that relying on IBE requires one to believe in the intelligibility of the world. If this is correct, it is surely absurd to maintain that we believe in the intelligibility of the world because we trust science. For one cannot 
trust science without trusting IBE, which is in turn impossible without believing in the intelligibility of the world. It is hence the other way around: we trust science and believe what it tells us about the world, because we take the world to be intelligible.

More plausibly, our belief in intelligibility is brought about by an intuitive seeming, rather than an inference. Lipton $(2004,206)$ confesses to finding it intuitively 'irresistible' to infer that a theory would successfully explain some evidence if true (and which admits of no equally endowed rival) is in fact true. Similarly, Bas van Fraassen $(1989,131)$ notes that the 'inference from phenomena that puzzle us to their best explanation appears to have our instinctive assent'. When faced with a novel fact, it is natural to wonder why said fact obtains, and the thought that it obtains for no reason at all strikes us as intuitively absurd. To reuse the example given earlier, I would find it intuitively very difficult to believe that nothing at all explains the appearance of little dark pellets on the floor and bite marks on the cheese.

I will therefore take it that our belief in the intelligibility of the world is an intuition, which I will call the intelligibility intuition.

\section{Naturalistic aetiologies of the intelligibility intuition}

An intuition may have a biological basis, and as such be innate, ${ }^{7}$ and a product of biological evolution. Alternatively, it may be acquired culturally. These are the only plausible options for a naturalistic aetiology of the intelligibility intuition. I consider each in turn, and argue that in both accounts, the truth of the intuition - that is, the actual intelligibility of the world - would have played no causal role in the processes that brought about the intuition itself.

\section{An evolutionary aetiology}

Donald Campbell (1960) aptly summarized biological evolution as consisting in 'blind variation and selective retention': random mutations produce new traits, which are retained or eliminated, depending on their consequences for the reproductive success of the organisms that have them. This second 'selective' component of evolution may be thought to undermine my argument's first premise. As W. V. O. Quine put it in an oft-quoted passage, 'Creatures inveterately wrong in their inductions have a pathetic but praiseworthy tendency to die before reproducing their kind' (Quine (1969), 126). Perhaps something similar can be said of abductions.

Suppose the world really is intelligible. If so, it could be argued, there would surely be some selective advantage in being disposed to believing as much. Creatures lacking this belief would not engage in abductive reasoning, and would thus miss out on the benefits of being able to understand their environments, and predict and manipulate them. Their chances of survival and reproduction would therefore be lower than those of creatures that did hold the relevant belief, everything else being equal. ${ }^{8}$ 
This Darwinian aetiology, then, appears to imply that the intelligibility intuition was selectively retained and passed down to us by virtue of being true. Being innately disposed to believe that the world is intelligible increased our prehistoric ancestors' reproductive success, because it is in fact the case that the world is intelligible. Thus, we seem to have a naturalistic aetiology of the intelligibility intuition such that the world's actual intelligibility brings it about that we have the intuition, against (1).

But the evolutionary account does not in fact have that implication, as I will now explain. The belief that the world is intelligible is a belief about the world $a s a$ whole, not a small subsection thereof. Granting that our ancestors would have benefited from knowing that their immediate environments were intelligible, what advantage would there have been in having true intuitions about the overall character of the world? As James Ladyman and Don Ross note, 'proficiency at inferring . . . any features of parts of the universe distant from our ancestral stomping grounds was of no relevance to our ancestors' reproductive fitness' (Ladyman \& Ross (2007), 2). At most, the evolutionary usefulness of the intuition is explained by the fact that it is true with respect to some facts relevant to our ancestors' survival and reproduction, not by the fact that it is true simpliciter.

It may be objected that creatures that failed to know that the world is intelligible would be incapable of engaging in scientific investigation, since they would refrain from seeking out explanations of natural phenomena (beyond those directly relevant to their immediate interests). As such, they would refrain from seeking out these explanations, and would thus be incapable of engaging in scientific investigation. Being deprived of the obvious technological and predictive benefits of science, they would be at clear disadvantage with respect to creatures that did possess the relevant knowledge about the explanatory structure of the universe.

Unfortunately, this reply would be incompatible with evolutionary theory, according to which traits are selectively retained if they benefit the individuals that have them - not their descendants living thousands of years after them. This is obvious when one remembers that the 'benefit' in question is increased reproductive success. The fact that some trait will increase the reproductive success of an individual's distant descendants could not possibly cause the trait to spread in the population containing said individual. And yet this is what would be required for the above scenario to be true. The first hominids to understand that the universe is amenable to scientific investigation would certainly not have benefited from this knowledge, simply because they could not themselves have carried out said investigation. Possessing science-enabling innate intuitions, though necessary, is not sufficient for science. To the contrary, science requires sophisticated instruments, techniques and institutions, which take hundreds, if not thousands, of years to develop. Thus, Bas van Fraassen writes that the evolutionary defence of IBE involves an empirically indefensible hypothesis of 'pre-adaptation', on which organisms adapt to life in future circumstances (van Fraassen (1989), 143). ${ }^{9}$ 
At this point, the proponent of the evolutionary aetiology may protest that even if there would have been no selection for accuracy with respect to the overall character of the world, there is still a sense in which we possess the intelligibility intuition because it is true. Indeed, an intelligible world is one in which prehistoric environments are intelligible, and hence one in which it would have been useful for our ancestors to have the intelligibility intuition. In other words, if the world is such that the intelligibility intuition is true, it will also be such that the intelligibility intuition is beneficial, and thus subject to natural selection. The fact that we would believe that $\mathrm{P}$ in all (or nearly all, or all nearby) worlds in which $\mathrm{P}$ may be thought to entail (and perhaps ground) the fact that we believe $\mathrm{P}$ because it is in fact the case that $\mathrm{P}$ - and thus that it is accurate to say that we hold the intelligibility intuition because it is true.

The following scenario illustrates why this objection cannot succeed: suppose I had the misfortune of eating a mushroom which happened to be poisonous and made me seriously ill. As a result, and given that this was the first and only mushroom I ever ate (and given the human tendency to extrapolate regularities from single instances), I form the belief that all mushrooms must be similarly poisonous, and recoil at the idea of ever eating another one. Now it is plain that in this case, I do not form the belief that all mushrooms are poisonous because it is in fact the case that all mushrooms are poisonous. The world's billions of other mushrooms weren't at all involved in bringing about my belief about them. This is so, even if every single existing mushroom happened to be poisonous - that is, if my newly formed intuition happened to be true. But notice that a world in which all mushrooms are poisonous is one in which this particular mushroom which I ate is poisonous, and is thus at least likely to be one in which I form the intuition that all mushrooms are poisonous. Hence, I would believe that all mushrooms are poisonous in all (or nearly all, or all nearby) worlds in which it is true that all mushrooms are poisonous. But, contrary to the objection, it still does not follow that I hold this believe because it is true. Likewise, the fact that the intelligibility intuition was selectively retained in our ancestral populations because it is true would not follow from the fact that all (or nearly all, or all nearby) intelligible worlds are ones in which we hold the intelligibility intuition.

A possible rejoinder is that the intelligibility of the world 'as a whole' explains the intelligibility of prehistoric environments, which in turn explains why the intelligibility intuition was selectively retained, entailing that the intelligibility of the world indirectly brought it about that we have intuition, and that (1) is false. But this is difficult to maintain, if one bears in mind that the intelligibility of the world is not a particular state of affairs that efficiently causes the intelligibility of prehistoric environments. Rather, it is the fact that the world's states of affairs, including those obtaining in prehistoric environments, at least generally have explanations for their obtaining. Some philosophers have suggested that there is some sense in which (some) regularities may explain their instances (cf. Loewer, 2012). But even admitting that there is some sense in which the intelligibility of states of 
affairs in general 'explains' the intelligibility of states of affairs relevant to reproductive success, it would still not follow that our possession of the intelligibility intuition is explained by the former. Consider again my 'mushroom' example: even if we grant that the poisonousness of all mushrooms 'explains' (in some sense) why this particular mushroom is poisonous, it is surely confused to say that the poisonousness of all mushrooms explains why I come to believe that all mushrooms are poisonous. For what role did the properties of, say, mushrooms in Russia (and all other countries I have never visited) play in bringing about my belief? None, surely. Similarly, the fact that the world 'as a whole' is intelligible could have played no role in bringing it about that we have the intelligibility intuition, even if there is some limited sense in which it explains why the environments of our prehistoric ancestors were intelligible. For only a very tiny proportion of all the instances of the general fact that states of affairs at least usually have explanations for their obtaining could have played any explanatory role in bringing it about that we have said intuition.

Nor would it help, of course, to deny that natural selection had anything to do with bringing it about that we have the intelligibility intuition. This would leave us with only the 'blind' component of evolution, that is, random mutation (and other non-selective mechanisms, such as genetic drift), which by definition does not produce traits by virtue of their usefulness to the organisms that have them (Merlin, 2010).

The point here is not that evolutionary forces cannot bring about intuitions that are true of the world as a whole, or even that they are unlikely to do so. ${ }^{10}$ Rather, the point is that if evolution did give us some intuition about the overall character of the world (such as the intuition that the world is intelligible), it would not do so because said intuition accurately represents the world. This is so whether or not the 'selective' component of evolution was involved.

I conclude that no evolutionary aetiology of the intelligibility intuition can constitute a counter-example to (1).

\section{A cultural aetiology}

Would a cultural account of the intelligibility intuition do a better job of securing a causal connection between the intuition's truth and our possession of it? It may initially seem so, because the worries raised for evolutionary aetiologies do not seem to apply.

Indeed, if the intelligibility intuition is a learned intuition spread by cultural processes (rather than an innate evolved one), perhaps it could have arisen at a time when having science-enabling metaphysical intuitions would have been beneficial. In that case, the above 'pre-adaptation' objection would have no bite.

It would be implausible for the naturalist to claim that it became advantageous for individuals to have a true metaphysical intuition about the explanatory structure of the world, because it enabled individuals to acquire many true scientific beliefs, and individuals with many true scientific beliefs reproduce more than 
those without them. In effect, high reproductive output seems perfectly compatible with having only very few true scientific beliefs, and many false ones. ${ }^{11}$

However, the naturalist could point out that human groups which engage in science tend to be more successful than those that don't. Indeed, human societies in which science is practised gain technological and predictive benefits, which may enable them to outcompete and overpower societies that don't.

In light of this, consider the following account of how cultural processes gave us the intelligibility intuition: prior to the advent of science, owing to cultural differences, some human groups were such that most of their members had the intuition that facts generally have explanations for their obtaining, whereas other human groups lacked this cultural trait. When societies became sufficiently advanced for scientific investigation to take place, those groups belonging to the former category set out to discover the explanations of many facts. Now as it happened, the world was intelligible in the relevant sense. As a result, these groups formed many true scientific theories, which allowed them to develop superior technology. In contrast, the groups without the intuitive expectation of intelligibility did not enjoy such technological progress. As a result, they were economically and militarily weaker than their scientifically informed counterparts, and were easily outcompeted for resources, either disappearing altogether or being absorbed into the more powerful groups. This is why virtually all human beings today have the intelligibility intuition.

On this account, the truth of the intelligibility intuition appears at least to contribute to explaining why we have it. The world's actual intelligibility, we are told, brings it about that having the intuition is advantageous, which in turn explains why we have it, against (1). This cultural aetiology is perhaps usefully thought of as involving a kind of 'cultural selection' of the intelligibility intuition: the trait was selectively retained by virtue of the technological benefits which it conferred on the groups that acquired it.

In truth, this parallel with biological evolution suggests that appealing to cultural evolution as a means of rebutting (1) faces a worry similar to the one we saw with respect to the evolutionary aetiology. For the intelligibility intuition need not at all be true in order to be useful. To see why, suppose that the world is not intelligible, containing very many brute facts. Suppose further that there is also a large number of facts such that (1) they are not brute and (2) discovering their explanations enables technological progress. Such facts could include, for instance, the fact that human beings sometimes fall ill, but are unlikely to include the fact that the dinosaurs no longer exist. Such a world would be one in which a capacity to engage in scientific investigation would surely be beneficial, in the sense of increasing a group's technological success - and thus one in which acquiring the intelligibility intuition would constitute a significant advantage to a sufficiently advanced society.

What this example illustrates is that the truth of the intelligibility intuition is causally irrelevant to the technological success of advanced societies, just as it is 
irrelevant to the reproductive success of prehistoric hominids. Both of these are perfectly compatible with the intelligibility intuition being false. Hence, the intuition could not have been selectively retained by virtue of being true, in the way described above.

Here again, and as with the evolutionary aetiology, one could respond that intelligible worlds are ones in which technologically relevant facts are intelligible, and thus ones in which having the intelligibility intuition is technologically useful, and that this is sufficient to legitimizing the claim that we have the intuition because it is true. But we have already seen why this objection fails: the fact that all (or nearly all, or all nearby) intelligible worlds are ones in which we have the intelligible intuition would not at all imply that we have the intuition because it is true.

I am not aware of an alternative cultural aetiology of the intelligibility intuition that could constitute a counter-example to (1). In the absence of such alternatives, I conclude that appeals to cultural evolution cannot undermine (1).

\section{Conclusion: (1) is motivated}

I have argued that given both evolutionary and cultural aetiologies of the intelligibility intuition, it is not the case that intelligibility of the world brings it about that we have the intelligibility intuition. Since these are the only plausible options consistent with naturalism, we may say that there are no naturalistic aetiologies of the intelligibility intuition given which this causal connection obtains, in line with (1).

It will shortly be argued that there is at least one kind of non-naturalistic aetiology that need not have the above implication-namely, a theistic aetiology, that is, one which involves the activity of the God of traditional theism. But I must first motivate the other premises of my main argument.

\section{MOTIVATING (2)}

(2) If (1) is correct, naturalists ought to withhold either the intelligibility intuition, or naturalism.

\section{The NCC Principle}

Suppose I believe that there is a cat on the mat. I hold this belief by virtue of a hallucinatory experience caused by the mushroom I ate earlier. As it turns out, my belief is true, because there is in fact a cat on the mat. Even so, there is surely something problematic about the way in which I formed my belief, regardless of its truth. One might say that it is true only 'by accident', that is, the truth of the belief has nothing to do with why I believe it. If I found out about the causal process that resulted in my believing that there is a cat on the mat, intuitively, I ought to withhold the belief. 
Examples such as this one illustrate the eminently plausible thought that the epistemic status of any given belief $\mathrm{P}$ is at least partly a function of one's background beliefs about how one formed P. More specifically, finding out that there is no appropriate causal connection between the truth of $\mathrm{P}$ and one's possession of P makes it illegitimate for one to continue to hold P. I stress 'appropriate' because not just any old causal connection will do. To adapt the above example, suppose the content of my hallucination included an experience of remembering that I had eaten a psychedelic mushroom. In this case, my belief that I have eaten the mushroom is the result of the fact that I did indeed eat the mushroom. Nonetheless, most would agree that my eating of the mushroom did not cause the resulting belief in the right way.

These general considerations would seem to apply to the more specific case of intuitions. The epistemic legitimacy of intuitions is of course hotly contested, with views ranging from near-total rejection to high permissiveness. But most, I take it, would agree that one's beliefs about the origins of any given intuition have an important bearing on the status of said intuition. Suppose I have the intuition that some religious scripture is the inspired word of God. My sociological research on the origins of the religious beliefs of my community lead me to believe that it is the result of purely natural processes. Most importantly, I form the belief that my co-religionists and I do not have the intuition that the scripture is divine because it is in fact the case that the scripture is divine. If this intuition happens to be true, it is so only 'by accident'. It seems clear enough that if I hold these background beliefs about the origins of my intuition, continuing to believe this intuition would be unjustified. ${ }^{12}$

I take the above example to illustrate the following epistemological principle:

No Causal Connection (NCC): if your background beliefs B about how your intuition that $\mathrm{P}$ was formed rationally require you to believe that you do not have the intuition that $\mathrm{P}$ because $\mathrm{P}$, you ought to withhold your intuition that $\mathrm{P}$ or $\mathrm{B} .{ }^{13}$

Note that NCC does not require an actual causal connection to obtain between $\mathrm{P}$ and the intuition that $\mathrm{P}$ for the latter to be justified. It is the subject's beliefs about how the intuition was formed that are relevant to its justification, not its actual aetiology. Nor does it say that the subject must have any background beliefs at all about how the intuition that $\mathrm{P}$ was formed. This would have the implausible implication that very young children cannot have any justified beliefs since they cannot represent their own beliefs.

Note finally that NCC outlines the appropriate causal connection for an intuition and the state of affairs that it represents. As such, it is not vulnerable to the objection (commonly levelled against principles of this type) that beliefs about future states of affairs obviously can be justified without being brought about (or believed to be brought about) by said states of affairs. Such beliefs are inferred from other beliefs, which are themselves usually about facts which will bring about the future state of affairs (such as when I predict that it is going to rain by seeing large clouds 
moving in my direction), or are causally connected to them in some other more complicated way. This cannot be the case for intuitions since they are, by definition, non-inferred.

\section{Applying the principle}

I argued that there is no plausible naturalistic aetiology of the intelligibility intuition such that the intelligibility of the world brings it about that we have the intuition - that is, that on all plausible aetiologies that are consistent with naturalism, the intelligibility intuition, if true at all, is so only 'by accident'. If this is correct, it appears that being a naturalist rationally requires one to believe that we do not have the intelligibility of the world because it is in fact the case that the world is intelligible. Hence, NCC compels the naturalist to withhold either the intelligibility intuition, or belief in naturalism, as per (2).

\section{MOTIVATING (3)}

(3) One should not withhold the intelligibility intuition.

I argued that relying on IBE requires one to believe that the world is intelligible, and that we believe this on the basis of intuition. These sections also mentioned that IBE plays a central role, not only in our everyday inferential practices, but in science as well: indeed, to distrust IBE would rationally require one to distrust science as a means of understanding the world. In view of this, withholding trust in IBE would seem very unattractive, perhaps just as unattractive as withholding trust in sense-perception, memory, and/or enumerative induction. It is thus safe to assume that few will wish to rebut my argument by denying that we ought to trust IBE. But if we ought to trust IBE, and if what I have said so far is correct, it follows that we ought not to withhold the intelligibility intuition, since this would be rationally incompatible with trusting IBE - hence (3).

It should be noted that not all philosophers accept that IBE, as I presented it earlier, is an adequate model of ampliative reasoning. Some claim that enumerative induction and/or Bayesian conditionalization sufficiently capture our inferential practises. A rebuttal of such 'anti-explanationism' is well beyond the scope of this article.

A more moderate stance, entertained by Lipton himself $(2004,112-120)$ and others, proposes that IBE is a heuristic that helps us to assign values to priors and likelihoods in Bayesian reasoning. For example, the extent to which some theory $T$ would explain some piece of evidence $e$ may be taken to indicate how likely $e$ would be given $T$. Thus, Samir Okasha (2000) suggests that $\mathrm{p}(e / T)$ be taken to roughly correspond to Lipton's 'explanatory loveliness'. Similarly, the prior probability of $T$ may be thought to depend partly on how well it explains facts other than the evidence under consideration. One may take this position, 
while also recognizing explanatory considerations are not infallible guides to likeliness, merely approximating Bayesian principles. Even so, Lipton notes that this view of the relationship between IBE and Bayesianism is reasonable only if one believes that 'loveliness is [at least] reasonably well correlated with likelihood'14 (ibid., 114, emphasis mine). Indeed, if no such correlation exists, loveliness will not even constitute a rough indication of Bayesian likelihoods and priors. But as we have seen, a world abounding with brute facts would not be one in which loveliness and likeliness are sufficiently correlated: in such a world, it would very often be the case that the true (or likeliest) theories are not the ones with the most explanatory power. Hence, reconciling IBE with Bayesianism does not appear to remove the commitment to the intuition that the world is 'intelligible', in the sense of being such that states of affairs at least generally have explanations for their obtaining.

\section{FROM AN ANTI-NATURALISTIC ARGUMENT TO A CASE FOR THEISM}

\section{A theistic aetiology of the intelligibility intuition}

I have advanced and motivated an argument to the effect that naturalists ought to withhold their belief in naturalism, because the only plausible naturalistic accounts of the intelligibility intuition imply that we do not have said intuition because it is true. This rationally compels naturalists either to withhold the intuition, or to replace their naturalistic background world-view with a non-naturalistic one. But naturalists should not opt for the former, as this would require them to withhold trust in IBE, which they cannot rationally do. Therefore, naturalists should opt for the latter and cease to be naturalists.

The argument, taken by itself, is not a theistic argument. However, it is easy to see how it could form part of a case for traditional theism, as long as it can be shown that theists are not similarly compelled to cease to be theists, for the same reasons. In particular, if it can be established that there is a plausible theistic aetiology of the intelligibility intuition such that we hold the intuition because it is true, we may conclude that there is no parallel anti-theistic argument. If, as is common in contemporary philosophy of religion, naturalism and traditional theism are taken to be the only options on the table, and assuming that there are no conclusive arguments against theism, this asymmetry would constitute a decisive consideration in favour of theism. As it happens, traditional theism can offer the desired kind of aetiology of the intelligibility intuition, as I will now show.

Suppose that the God of traditional theism, or something like it, exists. Such a being might well want its human creatures to discover many true explanations. And it would certainly have the power to ensure that their intuitive preferences in theory selection would enable them to do so. It could do so by setting up the fundamental natural facts in such a way that the natural processes shaping our cognitive capacities would give us true intuitions about the overall explanatory 
structure of the world, or by revealing these truths to us in a more direct way, through a kind of divine illumination. In either scenario, we intuit that the world is intelligible because it is in fact the case that the world is intelligible, since the source of the natural world intentionally brought it about that we would hold this intuition, since it is true.

It might of course be objected that the hypothesis of a being creating and sustaining an intelligible universe through sheer willpower is hardly plausible. This objection, while interesting, misses its mark. One may indeed find the idea of an immaterial being intentionally sustaining the existence of a material universe $e x$ nihilo utterly implausible. But for someone who accepts that such a being exists, there is nothing implausible about the thought that this being would intend for some of its creatures to have true innate philosophical intuitions, and act on this intention. The proposed aetiology is therefore plausible given theism. In contrast, I have argued that there are no aetiologies of the intelligibility intuition which are plausible given naturalism - that is, such that a committed naturalist should find them plausible - and such that the required causal connection obtains. Hence, the mysteriousness of divine causation does not eliminate the asymmetry between theism and naturalism with respect to the epistemological problem at hand. ${ }^{15}$

\section{Non-theistic non-naturalistic aetiologies}

This last point enjoys further support from the fact that at least some historically important non-naturalistic alternatives to traditional theism cannot provide plausible aetiologies establishing the required causal connection. I briefly consider three such alternatives.

\section{'Brahman'}

Suppose the natural order depended for its existence, not on an infinite Intellect as in traditional theism, but on a mindless, impersonal 'ultimate reality' which we may liken to a Vedic 'Brahman', or perhaps a Spinozist natura naturans from which the objects of the universe (i.e. natura naturata) derive their being (Nadler (2006), 119). Such a being would lack mental states, and therefore be devoid of intentions. It could not be maintained, then, that Brahman intended for us to have a true intuition about the world, and thus caused us to have the intelligibility intuition because it is true, since Brahman does not ever act intentionally. Therefore, believers in Brahman do not have access to the aetiology of the intelligibility intuition that preserves traditional theism from the epistemological problem faced by naturalists.

Perhaps there is some plausible 'brahmanic' aetiology of the intelligibility intuition such that the required causal connection obtains, though I am not aware of one. Note that it would not suffice to say that the natural order and all of its properties necessarily emanate from Brahman, and thus that Brahman necessitates that 
we have true innate philosophical intuitions (since such intuitions happen to be true, and we could not have failed to have them). For Brahman could also necessitate that I form a true belief that there is a cat on the mat as a result of eating hallucinogenic mushrooms (and not as a result of seeing the cat on the mat). It would be one thing for Brahman to cause me to form a true belief; for It to cause me to form a belief because it is true would be quite another.

\section{Polytheism}

Suppose instead that our cognitive capacities, and the innate intuitions that constitute them, were produced by beings that were themselves not causally responsible for the existence of the universe (perhaps Homeric gods, or powerful aliens). Such beings could certainly intend for us to have true innate intuitions, much like the God of traditional theism. However, there is an important difference between the ways God and the gods form the belief that the world is intelligible. God's belief that the world is intelligible is not problematic in the way that ours is. Indeed, since God is himself causally responsible for the intelligibility of the world, God's belief that the world has this feature need only be a matter of knowing himself - specifically, his creative activity, from which he may infer the relevant belief about the world. In that case, God's belief in the intelligibility of the world need not be an intuition, unlike ours, and hence the epistemological worries raised by the NCC principle for the intelligibility intuition do not apply to God. Indeed, it is clear that on this model, God's belief in the intelligibility of the world is appropriately causally connected to the state of affairs that it represents (given the type of belief that it is), since it is inferred from states of affairs (i.e. his creative activity) which causally bring it about that the world is intelligible. ${ }^{16}$

In contrast, a lesser 'god's' belief in the intelligibility of the world would not be the result of its own creative activity, and would therefore be subject to the same difficulties faced by our own belief in the intelligibility of the world. Thus, the proposed 'polytheistic' aetiology of the intelligibility intuition would not really solve the epistemological problem faced by naturalists, but merely push it back one step.

\section{Rationalism}

One final non-naturalist alternative to theism draws on a venerable philosophical tradition. One of the distinguishing characteristics of rationalist philosophers (as opposed to empiricist ones) is the role they ascribe to the faculty of rational intuition. This faculty, for rationalists, gives us direct epistemic access to certain basic logical, moral, or metaphysical truths, such that we can just 'see' that they are true (Markie, 2017).

Perhaps the intelligibility of the world is just one of those truths which we can just 'see' through rational intuition, which is a kind of intellectual perception. Now, it is clear that in cases of beliefs formed through veridical visual perception, the truth of the beliefs does contribute to explaining why we have them: the existence and features of my mug bring it about that I (correctly) form the belief that my mug is on my 
desk when I look at it. One may thus wish to push further the rationalist analogy between visual and intellectual perception, by claiming that the objects of intellectual perception somehow bring it about that we believe in them. Therefore, the intelligibility of the world somehow brings it about that we believe that the world is intelligible, and the required explanatory connection obtains.

There are at least two significant obstacles here. First, the hypothesis that we perceive the intelligibility of the world seems to have implausibly optimistic implications about our epistemological abilities. Indeed, what could it mean to say that I directly 'perceive' the fact that states of affairs generally have explanations for their obtaining, other than that I perceive the explanations of those facts? For example, it would mean that I perceive the explanation of the fact that salt dissolves in water - namely, the relevant dispositions of sodium and chloride ions. And to perceive such facts is to know them. The faculty to perceive explanatory loveliness through rational intuition would thus appear to enable me to know the explanations of states of affairs through rational intuition. But it is clear that rational intuition does not yield this kind of knowledge. If it did, there would be no need for $a$ posteriori science at all. ${ }^{17}$

Second, to perceive the fact that states of affairs at least generally have explanations for their obtaining is to perceive the fact that there are no (or very few) states of affairs which lack explanations. That is, it is to perceive the absence of any (or many) states of affairs which lack explanations. ${ }^{18}$ How is this possible? We may perhaps perceive the fact that there are no cookies left in the glass jar, by virtue of perceiving the boundaries of the jar. But the world is not a container inside which states of affairs obtain - rather, it is the collection of all existing states of affairs. Hence, there is no such thing as a 'world' existing over and above the states of affairs that obtain 'in' it, and the perception of which enables the perception of the absence (or quasi-absence) of states of affairs lacking explanations.

For these reasons, I am not convinced that the above rationalist aetiology can constitute a viable alternative to the theistic aetiology that I have provided.

\section{Comparisons with other arguments}

This section will explain some standard objections to prominent epistemological arguments for theism, and argue that whatever their independent merits, they do not threaten the case for theism defended here.

\section{Probabilistic arguments}

The opening section mentioned Alvin Plantinga's famous 'Evolutionary Argument Against Naturalism', which claims that the probability that our cognitive faculties are reliable is low, or at best inscrutable given evolutionary theory and metaphysical naturalism, and higher given traditional theism $(1993,2002)$. Although he intends this argument to apply to our cognitive faculties in general and doesn't single out any particular faculty or belief-forming method for debunking, others 
have tried to revise his argument in such a way as to restrict its scope. Of all such attempted revisions, most interesting for our purposes is Jeffrey Koperski's (2017). Koperski proposes that we reformulate Plantinga's basic argument into an argument targeting what he calls 'metatheoretic shaping principles' (MSPs), which are principles that 'help determine what good theories look like, as well as how one should proceed in their development'. They include the criterion of explanatory loveliness. Given our evolutionary origins (and metaphysical naturalism), we would not expect such MSPs to be reliable guides to scientific truth - in Lipton's (2004) terms, we would not expect loveliness to be a reliable guide to likeliness.

Thus, Koperski's argument resembles mine, insofar as both are epistemological arguments for theism which target IBE, and specifically the crucial assumption that the true theories are at least generally the loveliest theories. The arguments differ, however, insofar as my argument is not probabilistic. This renders my argument immune to an important objection which threatens Koperski's, as I will now argue.

\section{The inscrutability problem}

In considering whether theism would give us any grounds for expecting IBE to be reliable, Bas van Fraassen writes that 'even if he [i.e. God] created us naturally able to perceive the truth about what is important for us in his eyes (perhaps to discern love from lust, or charity from hypocrisy, in ourselves), this may not extend to speculations about demons, quarks, or universals' (van Fraassen (1989), 144). In other words, the theist cannot be confident that God would have ensured that we would have inferential practices which are truth-conducive with respect to scientific and philosophical matters. For all he knows, God had no intentions of doing so.

The theist is thus faced with the problem that the deity's intentions are to a large extent inscrutable, making it difficult to maintain that we would expect loveliness to be a reliable guide to likeliness given theism-call this the inscrutability problem.

The inscrutability problem is made more acute by the extensive evidence of evil in the world. Evan Fales rhetorically asks in response to Plantinga's argument, 'If God can see fit to allow small children to die of terrible diseases for some greater good we cannot imagine, might He not have given us radically defective cognitive systems, and allowed us to be lulled into thinking them largely reliable, also for some unimaginable reason?' (Fales (2002), 56).

The occurrence of such terrible evils suggests that God's intentions may be opaque to us, especially if we cannot conceive of sufficient reasons that God might have for allowing these evils. But in that case, it is not clear whether it can be maintained that the reliability of treating explanatory loveliness as a guide to truth is more to be expected given theism than given naturalism, ${ }^{19}$ in which case Koperski's argument would fail to show that the atheist is in an epistemically worse position with respect to IBE. One may respond with a theodicy, 
that is, an account of why a perfect being would create a world which contains terrible evils. Such an account would show that such evils are not in fact particularly surprising given theism, in which case God's intentions might not be so inscrutable after all. But this response would only be as good as the proposed theodicy. ${ }^{20}$

Fortunately, my epistemological case for theism does not at all involve the claim that, given theism, we ought to expect explanatory loveliness to be a reliable guide to truth. (2) claims that naturalists ought to withhold the intuition that this is the case (or their background commitment to naturalism), not for any probabilistic reasons, but because there are no plausible naturalistic aetiologies such that our possession of this intuition and the state of affairs that it represents are causally connected in a way that would be epistemically appropriate. In contrast, there is a plausible theistic aetiology that has this implication. Crucially, to say that this aetiology is plausible is not to say that it is more probable than not, or more probable than each of its theistic rivals. Rather, it is simply to say that God could plausibly have intended for us to have true innate intuitions about the world. One can coherently affirm this, while also affirming that God's will is inscrutable. Hence, the inscrutability problem does not arise for my argument, which is surely an advantage.

\section{God and the third realm}

Other cases of pernicious epistemic luck have been thought to admit of theistic solutions.

On some views, mathematical and/or moral states of affairs involve abstract objects which form part of a causally isolated 'third realm' (otherwise known as 'platonic heaven'). Critics charge that this would make knowledge of moral and/ or mathematical facts impossible (cf. Benacerraf, 1973). Surely, for such facts to be known at all, there must be some causal connection between the facts and our knowledge of them. But the nature of these facts necessarily precludes this. Thus, if our basic mathematical and moral intuitions are true, they are only so by virtue of a pernicious fluke of epistemic luck, and hence cannot constitute knowledge.

Some argue that this sort of sceptical challenge admits of a theistic solution (e.g. Adams, 1983): God, being omnipotent, could have ensured that our basic mathematical and moral intuitions would accurately represent the abstract states of affairs they are supposed to represent. In that case, our possession of true mathematical and moral intuitions would not be the result of a pernicious fluke of epistemic luck, and therefore can constitute knowledge.

Critics such as Dan Baras (2017) respond that this purported theistic solution would only, as it were, push the problem one step back, because we are now left with the challenge of explaining God's knowledge of moral and mathematical truths. Even if God's basic moral and mathematical beliefs are true, such beliefs cannot on platonism be in any way causally connected to the facts they represent (however accurately). But if God does not have his particular moral and mathematical beliefs because they are true, the fact that these beliefs of his happen to be 
true is itself a coincidence. If so, the proposed theistic account of the origins of our moral and mathematical intuitions does not after all show that the truth of such intuitions is not an epistemically problematic happy coincidence.

It may initially be thought that the theistic aetiology of the intelligibility intuition proposed earlier faces a similar worry, since it too invokes divine activity to establish an epistemically appropriate causal connection that would otherwise be lacking. I submit that it does not, because the fact that the world is intelligible, if it obtains, would not be a causally isolated 'platonic' fact. Rather, it is a concrete fact which is causally brought about by God if he exists. God believes that the world is intelligible because he is himself causally (and intentionally) responsible for its being true. Thus his belief in the intelligibility of the world surely is appropriately connected to the state of affairs that it represents.

The worry with the intuition that the world is intelligible is not that it in principle impossible for the world's intelligibility to be appropriately causally related to any subject's belief in it. Rather, the worry is that our belief in the intelligibility of the world, by virtue of our particular position in the causal nexus, does not look like it could be appropriately connected to the state of affairs which it represents, unless theism (or something sufficiently like theism) is true.

I conclude that my argument is not threatened by this objection to epistemological arguments for theism pertaining to knowledge of the third realm. This too is a significant advantage. ${ }^{21}$

\section{Conclusion: a new direction for the Cartesian project}

Descartes famously argued that the truth of 'clear and distinct' ideas was guaranteed by the goodness of the God who formed our cognitive capacities. Many have drawn inspiration from Descartes in putting forward arguments to the effect that, if God exists, we would expect God to ensure that our basic belief-forming methods are reliable, whereas we would have no such assurance given atheism. We saw that this sort of argument, whether in its original Cartesian form or in that of its Plantingian successor, faces the serious objection that the existence of apparently gratuitous evils apparently makes God's intentions inscrutable, which would make void the epistemological assurance that theism was supposed to provide.

Others have instead contended that the existence of a perfect being eliminates the pernicious epistemic luck that we would otherwise need in order to form true beliefs about abstract states of affairs. But here again, and as we have seen, it appears that appealing to theism only pushes the initial problem one step back, since it would also have taken a happy coincidence for God's beliefs about the third realm to be true.

The epistemological case for theism advanced here avoids both of these limitations. I have indeed argued that a naturalistic background world-view compels one to withhold the intuition that the world is intelligible-not because the 
intelligibility of the world is an abstract state of affairs, or because the intuition's truth is unlikely given naturalism, but because there are no plausible accounts of the origins of the intuition that are consistent with naturalism and which establish an epistemically appropriate causal connection between said intuition and the state of affairs which it represents. This in turn compels naturalists to withhold trust in abductive reasoning, which relies on the intuition, or cease to be naturalists. Traditional theism, in contrast, does not force us into this unpleasant epistemological predicament, since it offers an aetiology of the intelligibility intuition that secures the required causal connection. This is surely strong grounds for preferring traditional theism over naturalism, as well as the non-naturalistic non-theistic alternatives discussed in this article.

I expect that parallel arguments could be made for theism with respect to other intuitions involved in our basic belief-forming practices (such as, perhaps, the intuition that nature is uniform, on which induction is often thought to depend). I conclude with the suggestion that those wishing to embark (or already embarked) on what one might call the 'Cartesian project' - that is, the endeavour to argue for theism by identifying its epistemological advantages ought to look in that direction. ${ }^{22}$

\section{References}

Adams, R. (1983) 'Divine necessity', The Journal of Philosophy, 80, 741-752.

BARAs, D. (2017) 'A reliability challenge to theistic Platonism', Analysis, 78, 479-487.

BeILBy, J. K. (ed.) (2002) Naturalism Defeated? Essays on Plantinga's Evolutionary Argument against Naturalism (Ithaca NY: Cornell University Press).

Benacerraf, P. (1973) 'Mathematical truth', The Journal of Philosophy, 7o, 661-679.

BOYER, P. (2000) 'Natural epistemology or evolved metaphysics? Developmental evidence for early-developed, intuitive, category-specific, incomplete, and stubborn metaphysical presumptions', Philosophical Psychology, 13, 277-297.

CAmpBell, D. (1960) 'Blind variation and selective retentions in creative thought as in other knowledge processes', Psychological Review, 67, 380-400.

CARRUTHERs, P. (2006) The Architecture of the Mind: Massive Modularity and the Flexibility of Thought (Oxford: Clarendon Press).

DE RAY, C. (2020) 'An evolutionary sceptical challenge to scientific realism', Erkenntnis.

Descartes, R. (1641) [1996] Meditations on First Philosophy with Selections from Objections and Replies, J. Cottingham (tr. \& ed.) (Cambridge: Cambridge University Press).

Dougherty, T. (2011) 'Recent work on the problem of evil', Analysis, 71, 560-573.

Draper, P. (2005) 'God, science and naturalism', in W. J. Wainwright (ed.) The Oxford Handbook of Philosophy of Religion (Oxford: Oxford University Press), 272-303.

FALES, E. (2002) 'Darwin's doubt, Calvin's calvary', in J. Beilby (ed.) Naturalism Defeated? Essays on Plantinga's Evolutionary Argument against Naturalism (Ithaca NY: Cornell University Press), 43-60.

Graber, A., \& Golemon, L. (2019) 'Plantinga redux: is the scientific realist committed to the rejection of naturalism?', Sophia, 59, 395-412.

Isserow, J. (2018) 'Evolutionary hypotheses and moral skepticism', Erkenntnis, 84, 1025-1045.

Kaufmann, E. (2010) Shall the Religious Inherit the Earth? (London: Profile Books).

KIM, J. (2010) Essays in the Metaphysics of Mind (Oxford: Oxford University Press).

Koons, R. (2000) 'The incompatibility of naturalism and scientific realism', in W. L. Craig \& J. P. Moreland (eds) Naturalism: A Critical Analysis (Abingdon: Routledge), 49-63.

Koperski, J. (2017) 'Theism, naturalism, and scientific realism', Epistemology and Philosophy of Science, 53, 152-166. 
Korman, D. Z. (2019) 'Debunking arguments in metaethics and metaphysics', in A. Goldman \& B. McLaughlin (eds) Metaphysics and Cognitive Science (Oxford: Oxford University Press), 337-363.

Ladyman, J. \& Ross, D. (2007) Every Thing Must Go: Metaphysics Naturalized (Oxford: Oxford University Press). Lipton, P. (2004) Inference to the best explanation, 2nd edn (London: Routledge).

LocKE, D. (2014) 'Darwinian normative scepticism', in M. Bergmann \& P. Kain (eds) Challenges to Moral and Religious Belief: Disagreement and Evolution (Oxford: Oxford University Press), 220-236.

Loewer, B. (2012) 'Two accounts of laws and time', Philosophical Studies, 160, 115-137.

Markie, P. (2017) 'Rationalism vs. empiricism', in E. Zalta (ed.) Stanford Encyclopedia of Philosophy, <https:// plato.stanford.edu/entries/rationalism-empiricism/> [accessed 15 July 2020].

McMuluin, E. (1992) The Inference That Makes Science (Milwaukee WI: Marquette University Press).

МсNАвв, Т. (2015) 'Defeating naturalism: defending and reformulating Plantinga's EAAN', Eleutheria, 4, 35-51.

MerLIN, F. (2010) 'Evolutionary chance mutation: a defense of the modern synthesis' consensus view', Philosophy and Theory in Biology, 2, 1-22.

NADLER, S. (2006) Spinoza's 'Ethics': An Introduction (Cambridge: Cambridge University Press).

NAGel, T. (2012) Mind and Cosmos: Why the Materialist Neo-Darwinian Conception of Nature is Almost Certainly False (Oxford: Oxford University Press).

Nieminen, P., Boudry, M., Ryokas, E., \& Mustonen, A. (2017) 'Biblical and theistic arguments against the evolutionary argument against naturalism', Zygon, 52, 9-23.

Оказна, S. (2000) 'Van Fraassen's critique of inference to the best explanation', Studies in History and Philosophy of Science Part A, 31, 691-710.

Plantinga, A. (1993) Warrant and Proper Function (Oxford: Oxford University Press).

Plantinga, A. (2002) 'Reply to Beilby's cohorts', in J. Beilby (ed.) Naturalism Defeated? Essays on Plantinga's Evolutionary Argument against Naturalism (Ithaca NY: Cornell University Press), 204-275.

Plantinga, A. (2011) Where the Conflict Really Lies (New York: Oxford University Press).

Psillos, S. (1999) Scientific Realism: How Science Tracks the Truth (Abingdon: Routledge).

Quine, W. V. (1969) 'Natural kinds', in J. Kim \& E. Sosa (eds) Ontological Relativity and Other Essays (New York: Columbia University Press) 114-138.

RoEBER, D. (2009) 'Does the theist have an epistemic advantage over the atheist?', Journal of Philosophical Research, 34, 305-328.

Sober, ElLiott (1990) 'Explanation in biology: let's razor Ockham's razor', Royal Institute of Philosophy Supplement, 27, 73-93.

van FraAssen, B. (1989) Laws and Symmetry (Oxford: Oxford University Press).

\section{Notes}

1. Plantinga's argument has spawned a vast literature. Many of the most important objections and rebuttals may be found in Beilby (2002).

2. Metaphysical naturalism should be distinguished from methodological naturalism, which holds that one should not posit any entity, property, or process that has not been shown to exist by our best science (cf. Draper, 2005). Providing a satisfactory account of what counts as 'natural' has of course proved difficult. Draper (ibid.) characterizes the natural order as 'the spatiotemporal universe of physical entities together with any entities that are ontologically or causally reducible to those entities'. While this rules out God and Cartesian minds, it also excludes platonic abstracta, the existence of which may be thought to be consistent with naturalism. Even so, this definition is acceptable for our purposes, at least as a first approximation.

3. Where 'God' may be taken to refer to the 'perfect being' of historic Christian theism, or something sufficiently similar to it.

4. Similarly, Thomas Nagel $(2012,17)$ unpacks the assumption of the 'rational intelligibility of the world' as the assumption that 'the explanation that gives greater understanding is more likely to be true'. He also describes it as a variant of the traditional 'principle of sufficient reason' (ibid.).

5. Arguably, relying on IBE requires one to believe not only that states of affairs generally have explanations, but that we enjoy epistemic access to these explanations. I will only concern myself with the former requirement here.

6. Similarly, Stathis Psillos argues that scientific realism, the view that our best theories are at least approximately true, commits one to the claim that abductive methods 'tend to generate approximately true beliefs and theories' (Psillos (1999), xxi), and thus to the reliability of IBE. 
7. Some cognitive scientists argue that human cognitive systems are constituted by 'modules' which predispose us to form certain beliefs about the overall character of the world - that is, to have what is sometimes called an 'intuitive ontology' (Boyer, 2000).

8. This account of the origins of the intelligibility intuition enjoys some support from evidence to the effect that human beings are innately disposed to reason abductively (cf. Carruthers, 2006). If it is true that running abductive inferences requires one to expect facts to have explanations, a biological propensity to reason abductively would have to include an innate disposition to expect facts to have explanations.

9. Cf. Graber \& Golemon (2019) and de Ray (2020) for more developed discussion of evolutionary defences of IBE.

10. In consequence, the main contention of this section is entirely consistent with the claim that we would expect true innate philosophical intuitions to have evolved as an evolutionary 'by-product' of selection for some other trait (cf. de Ray (2020) for a recent discussion of this claim).

11. In fact, scientifically illiterate religious communities often have impressively high reproductive rates, which leads some to hypothesize that non-scientific modes of thinking will eventually sweep over the world (Kaufmann, 2010).

12. This example was borrowed from de Ray (2020).

13. Cf. Locke (2014), Isserow (2018), Korman (2019), and de Ray (2020) for similar principles. I take it that to 'withhold' an intuition consists at the very least in distrusting it, if one cannot rid oneself of it. Principles of this kind are sometimes criticized on the grounds that they cannot account for justified beliefs about abstract 'platonic' facts. Though this issue is beyond the scope of this article, I'm inclined to believe that this says more about platonism than about causal epistemological principles. In any case, it is not clear that such abstracta are consistent with naturalism (cf. note 2).

14. This also applies to priors, since these are also determined by explanatory considerations according to Lipton (ibid., 115).

15. This type of rejoinder might hold water if I was arguing, say, that the naturalist faces an 'explanatory gap', being unable to explain how purely natural processes could produce minds with true philosophical intuitions.

16. It may be asked: how does God form the belief that his creative activity is successful in achieving its aims? If we take God's omnipotence to be a concrete divine attribute (rather than a platonic abstractum), there is in principle no reason why God's omnipotence couldn't bring about God's belief that he is omnipotent, perhaps through an act of divine self-perception.

17. The point here is not that one cannot have some kind of a priori insight that the world as a whole must be lovely, without also having a priori knowledge of all scientific facts. Rather, the point is that such insight cannot consist in the perception of the world's loveliness, without also consisting in the perception of such facts.

18. Compare: to perceive that everyone in the office has hair is to perceive the fact that no one in the office is bald.

19. See Roeber (2009) for a more developed argument along similar lines. See also Nieminen et al. (2017), in which it is argued that biblical theists are at no advantage compared to atheists, since the Bible contains episodes in which God deceives human beings.

20. See Dougherty (2011) for a helpful overview of recent work on the problem of evil.

21. There is a third advantage, which I will only briefly mention here: some have argued that metaphysical naturalists cannot justifiably hold to some version or the other of the principle of parsimony, according to which 'simpler' candidate theories are more likely to be true, for reasons analogous to the ones put forward here with respect to explanatory loveliness (cf. Koons, 2000; Graber \& Golemon, 2019). The significance and nature of parsimony in theory choice is a matter of considerable controversy, with some denying that a theory's 'simplicity' (in and of itself) increases its likeliness at all (e.g. Sober, 1990). Fortunately, the success of my argument does not depend on any claim about the role of parsimony in IBE. It instead depends on the weaker and far less controversial contention that, in IBE, explanatory loveliness (which may or may not include 'simplicity') is taken as an indicator of likeliness.

22. I am grateful to Alexander Bird, Jørgen Dyrstad, Eileen Pfeiffer, and Robert Harold for their helpful comments on my work, as well as to the Arts and Humanities Research Council (AHRC) for its support. 